\title{
Controlling bacteria retention on polymer via replication of laser micro/nano textured metal mould
}

DOI:

10.1016/j.optlastec.2018.10.031

\section{Document Version}

Accepted author manuscript

Link to publication record in Manchester Research Explorer

\section{Citation for published version (APA):}

Rajab, F. H., Liu, Z., Wang, T., \& Li, L. (2019). Controlling bacteria retention on polymer via replication of laser micro/nano textured metal mould. Optics and Laser Technology, 111, 530-536.

https://doi.org/10.1016/j.optlastec.2018.10.031

\section{Published in:}

Optics and Laser Technology

\section{Citing this paper}

Please note that where the full-text provided on Manchester Research Explorer is the Author Accepted Manuscript or Proof version this may differ from the final Published version. If citing, it is advised that you check and use the publisher's definitive version.

\section{General rights}

Copyright and moral rights for the publications made accessible in the Research Explorer are retained by the authors and/or other copyright owners and it is a condition of accessing publications that users recognise and abide by the legal requirements associated with these rights.

\section{Takedown policy}

If you believe that this document breaches copyright please refer to the University of Manchester's Takedown Procedures [http://man.ac.uk/04Y6Bo] or contact uml.scholarlycommunications@manchester.ac.uk providing relevant details, so we can investigate your claim.

\section{OPEN ACCESS}




\section{Manuscript Details}

\section{Manuscript number}

Title
JOLT_2018_785_R1

Controlling bacteria retention on polymer via replication of laser micro/nano textured metal mould

Research Paper

\section{Article type}

Abstract

Polymer materials including paints and objects are widely used in our daily life. Keepping them free from bacteria without the use of any actibacterial agents is of high interest to the public. In this paper, we demonstrate a method for significantly reducing bacteria adhesion and growth on a polymer surfaces by generating a specific surface micro/nano structure. A metallic template was prepared using laser micro/nano surface texturing on Ti6Al4V surfaces. Then the negative surface structure was transferred onto a polydimethylsiloxane (PDMS) polymer using soft lithography. Staphylococcus aureus (S. aureus) retention assays were used to determine the number of retained bacteria on the replicated polymer surfaces. Results showed that on all the replicated plastic surfaces, the number of adhesive bacteria was much reduced (up to a fivefold reduction) compared to that on the non-textured polymer surfaces. This was largely due to the reduced wettability with a water contact angle close to $150 \square$ on the replicated polymer surface that contained specific micro/nano structures. This finding could lead to potentially applications for reducing bacteria adhesion or fouling on painted surfaces (e.g. ship hulls) and plastic objects (e.g. phones and computer keyboards) using nanostructure transfer from metal templates by, for example, stamping and hot/cold embossing and injection moulding.

Keywords

Manuscript category

Corresponding Author

Order of Authors

Suggested reviewers
Picosecond laser, PDMS, wettability, bacteria adhesion.

Laser

Fatema Rajab

Fatema Rajab, Zhu Liu, Tao Wang, Lin Li

Koji Sugioka, Minlin Zhong, Tahseen jwad

\section{Submission Files Included in this PDF}

\section{File Name [File Type]}

Responses_to_reviewers comments.docx [Response to Reviewers]

highlights.docx [Highlights]

Manuscript.docx [Manuscript File]

To view all the submission files, including those not included in the PDF, click on the manuscript title on your EVISE Homepage, then click 'Download zip file'. 


\section{Controlling bacteria retention on polymer via replication of laser micro/nano textured metal mould}

We would like to thank the reviewers for their useful comments and suggestions. We have addressed all the comments point-by-point and modified the paper accordingly. The following table provides a summary of the authors' responses

\section{Responses of the Authors to the Comments by the Reviewers}

\begin{tabular}{|c|c|c|}
\hline & Comments of Reviewer & Response of the authors \\
\hline 1 & $\begin{array}{l}\text { This manuscript reports an investigation on anti- } \\
\text { bacteria performance of embossed PDMS } \\
\text { surfaces with micro-nano structures via a Ti6Al4V } \\
\text { template produced by a ps laser. Two PDMS } \\
\text { replica surfaces with different micro-nano } \\
\text { structures and then different surface roughness } \\
\text { and features were compared to the PDMS replica } \\
\text { surface of the original flat Ti6Al4V surface } \\
\text { referring to their response to retained bacteria } \\
\text { by Staphylococcus aureus (S. aureus) retention } \\
\text { assays. Their results indicate that the micro-nano } \\
\text { structured PDMS surface with higher surface } \\
\text { roughness can obviously reduce the bacteria } \\
\text { adhesion number compared to the structured } \\
\text { PDMS surface with lower roughness, both better } \\
\text { than the PDMS replica of flat surface. The authors } \\
\text { attributed these results to the improved } \\
\text { hydrophobicity of those surfaces after printed } \\
\text { micro-nano structures. Although it is well } \\
\text { approved by available publications that specific } \\
\text { surface micro-nano metallic structures can } \\
\text { improve the anti-bacteria performance, this } \\
\text { manuscript offers somewhat interesting results. } \\
\text { While the results are solid and looks reliable, I am } \\
\text { not satisfied by the current explanation and } \\
\text { analyses on the results. The authors mentioned } \\
\text { the larger surface area or surface topography } \\
\text { may be the reason but attributed mainly the }\end{array}$ & $\begin{array}{l}\text {-In this work, the relationship between surface wettability } \\
\text { and bacterial behavior has been studied. It has been } \\
\text { proved that the surface of high wettability attracted } \\
\text { bacteria more than the surface of low and moderate } \\
\text { wettability after } 24 \text { hrs. Yes, as the reviewer mentioned } \\
\text { that the surface features was bigger than the bacteria size } \\
\text { as shown in figure } 5 \text {. However, the same figure showed } \\
\text { that the bacteria spread over the replicated PDMS } \\
\text { surfaces with lower number comparing with nontextured } \\
\text { PDMS surface while the bacteria attached to the control } \\
\text { surfaces were arranged in clusters. The experiment was } \\
\text { repeated in triplicate and the bacteria incubation was for } \\
24 \text { hrs. Indeed, figure } 2 f \text { indicated that the large } \\
\text { nonuniform included small features. These features were } \\
\text { the replication of sub-micron features of figure } 2 c \text {. these } \\
\text { features might help in increasing the air trapping between } \\
\text { features and impeding the bacteria attachment and } \\
\text { growth. }\end{array}$ \\
\hline
\end{tabular}




\begin{tabular}{|c|c|c|}
\hline & $\begin{array}{l}\text { reason to the increased surface hydrophobicity, } \\
\text { that surface of higher hydrophobicity is more } \\
\text { able to resist the bacterial cells compared with } \\
\text { hydrophilic and moderate hydrophobic surfaces. } \\
\text { This is true and seemly indicated by other } \\
\text { published works that surfaces hydrophobicity } \\
\text { play an important role in reducing the bacterial } \\
\text { attachment. When we look at the images in Fig } 5 \\
\text { that the bacteria is so small (around 700nm) } \\
\text { compared to the rough surfaces, in which how } \\
\text { the entrapped air between roughening features } \\
\text { can reduce the contact area at the interface. It is } \\
\text { obviously different from the Cassie state that } \\
\text { more air can be entrapped between the much } \\
\text { larger water droplets and the rough surface. I } \\
\text { would prefer the authors provide more evidence } \\
\text { (experimental results or analysis) on this issue } \\
\text { before I recommend to accept this manuscript. }\end{array}$ & \\
\hline 2 & $\begin{array}{l}\text { One minor issue: in Fig } 4 \text {, the authors may need } \\
\text { to indicate how long after the laser structuring } \\
\text { when the CA measurement is taken, since the CA } \\
\text { of a laser structured surface will increase when } \\
\text { kept in air for longer time. }\end{array}$ & $\begin{array}{l}\text {-The contact angles of laser treated surfaces were } \\
\text { measured after one month of laser structuring and this } \\
\text { has been included in the paper. }\end{array}$ \\
\hline
\end{tabular}




\section{Highlights}

1. Structures from the metallic master can efficiently be replicated to the plastic replica using the soft replication technique.

2. The roughness of the laser treated metallic surfaces was increased after laser treatment and the roughness of the replicated PDMS surfaces was higher than the roughness of the non-textured PDMS surface.

3. The laser-irradiated Ti-alloy formed hydrophobic surfaces whereas the wettability of the replicated PDMS surface was close to the superhydrophobicity.

4. The number of adhered bacteria was much reduced on the replicated polymer textured surfaces compared to that on the non-textured polymer surfaces.

5. The approach of laser surface structuring and soft replication provides an efficient strategy for producing hydrophobic and antiadhesive surfaces on polymeric materials. 


\title{
Controlling bacteria retention on polymer via replication of laser micro/nano textured metal mould
}

\author{
Fatema H. Rajab ${ }^{1,2^{*}}$, Zhu Liu' ${ }^{1,3}$, Tao Wang ${ }^{4}$ and Lin Li ${ }^{1}$ \\ ${ }^{1}$ Laser Processing Research Centre, School of Mechanical, Aerospace and Civil Engineering, \\ The University of Manchester, Manchester, M13 9PL, UK \\ ${ }^{2}$ College of Engineering, Al-Nahrain University, Baghdad, Iraq \\ ${ }^{3}$ School of Materials, The University of Manchester, Manchester M13 9PL, UK
}

${ }^{4}$ Faculty of Biology, Medical and Healthcare, The University of Manchester, Manchester M13 $9 P L, U K$

Corresponding authors*Fatema H. Rajab, fatema.rajab@postgrad.manchester.ac.uk, fatemarajab83@gmail.com; Tel: +44 (0)7769769657

\begin{abstract}
Polymer materials including paints and objects are widely used in our daily life. Keepping them free from bacteria without the use of any actibacterial agents is of high interest to the public. In this paper, we demonstrate a method for significantly reducing bacteria adhesion and growth on a polymer surfaces by generating a specific surface micro/nano structure. A metallic template was prepared using laser micro/nano surface texturing on Ti6A14V surfaces. Then the negative surface structure was transferred onto a polydimethylsiloxane (PDMS) polymer using soft lithography. Staphylococcus aureus (S. aureus) retention assays were used to determine the number of retained bacteria on the replicated polymer surfaces. Results showed that on all the replicated plastic surfaces, the number of adhesive bacteria was much reduced (up to a fivefold reduction) compared to that on the non-textured polymer surfaces. This was largely due to the reduced wettability with a water contact angle close to $150^{\circ}$ on the replicated polymer surface that contained specific micro/nano structures. This finding could lead to potentially applications for reducing bacteria adhesion or fouling on painted surfaces (e.g. ship hulls) and plastic objects (e.g. phones and computer keyboards) using nanostructure transfer from metal templates by, for example, stamping and hot/cold embossing and injection moulding.
\end{abstract}

Keywords: Picosecond laser, PDMS, wettability, bacteria adhesion. 


\section{Introduction}

Biofilm formation and colonisation are initiated by bacterial attachment to the surfaces followed by bacterial adhesion and retention on the surface. The build-up of biofilms may result in health problems in the medical field and potential biofouling issues in industrial settings. Efforts were taken to control the behaviour of bacteria. The first step of bacterial attachment to a surface is goverened by physicochemical factors which are affected by surface chemistry and topography [1]. In the literature, conflicting results about the influence of hydrophobicity on initial bacterial attachment are found [2-13]. Another step of bacterial adhesion and retention to a surface is influenced by the substratum roughness and topography [1, 8-12]. Many studies have been carried out to investigate the effect of surface topography on bacterial retention [5-12, 14-20]. Some of the reported works focused on studying the bacterial behaviour on polymer surface [812]. However, the exact influence of surface properties on bacterial retention is still poorly understood. Topographic properties of a surface may be characterised by using an average surface roughness value $\left(R_{a}\right)$. Other roughness parameters, such as $R_{q}$ (root-mean-square roughness) or $R_{p v}$ (peak to valley roughness), may be used to describe surface topographical characteristics. The geometrical shape and surface free energy of the surface features also affect the bacterial behaviour $[1,4,8-12,21,22]$.

Forming micro/nanostructures by texturing surfaces have been used in a wide range of applications. For example, it has been used for modifying the optical properties and the wettability characteristics of surfaces, controlling cells adhesion and proliferation, and modifying bio-implants [13, 23-26]. Different techniques, such as photolithography, moulding, machining, laser-texturing and plasma treatment have been used to generate different surface topographical characteristics [27]. Laser processing has the advantage of providing diverse, relatively simple and environmentally friendly solutions $[28,29]$.

From an economic perspective, surface micro-/nano-texturing could be cost effective for small areas [30]. Thus, the development of low-cost as well as highly reproducible micro/nano surface texturing techniques has been receiving growing attention. However, as the production of large area micro/nanostructures takes considerable amount of time, replication on plastic surfaces using the metal moulds would be a far more productive and economical method to produce textured surfaces [31]. The development of a moulding technique to produce numerous replicas 
of functional structures is a possible way forward for practical biological and industrial applications [31].

The replication of laser textured surfaces on polymer surfaces has been reported using several replication processes like injection mould and soft lithography [32-40]. The authors in the cited works focused on studying the wettability and transparency characteristics of the generated polymer replicas. Moreover, the effect of laser surfaces structuring of metallic substrates on bacterial behaviour have been reported [5-7, 13]. However, limited number of work has been reported on studying the adhesion and fouling characteristic of replicated laser textured metallic surfaces on polymer [41]. Therefore, in this study, a picosecond laser was used to generate a range of micro/nano surface topographies on Ti substrates. This was followed by the application of soft lithography to negatively replicate the Ti structures on polydimethylsiloxane PDMS plastic substrates. The effects of micro/nanostructures replication on wettability and bacteria retention were characterised and discussed.

\section{Material and methods}

\subsection{Surface preparation}

Prior to laser treatment, Ti6Al4V (Ti-alloy) sheet (master molds) of $1 \mathrm{~mm}$ thickness was ultrasonically cleaned by immersion for 10 minutes in acetone, ethanol and de-ionised water, respectively. Subsequently, two Ti6Al4V master molds were prepared by surface texturing using an Edge Wave picosecond laser (ps) at a $1064 \mathrm{~nm}$ wavelength, a $103 \mathrm{kHz}$ repetition rate, a $125 \mu \mathrm{m}$ spot size and a $10 \mathrm{ps}$ pulse duration in the air with no assisting gas (Table 1). The laser beam scanning was performed using parallel line patterning. By using to different laser processing parameters two surfaces were produced: low roughness surface using high speed and fluence and high roughness surface using low speed and fluence. After the laser treatment, the samples were ultrasonically cleaned with ethanol for 10 minutes to remove any ablated debris or contamination and then they were dried using compressed air. A negative replica of laser-fabricated Ti6A14V structures was produced on PDMS (SYLGARD 184, DOW CORNING). A viscous liquid prepolymer of PDMS was prepared by mixing a curing agent in a ratio of 10:1 v/v. Subsequently, the mixture was placed into a vacuum chamber to remove any residual air bubbles. Afterwards, the original laser-textured Ti6A14V surfaces, as well as the untreated surfaces (control), were covered with the prepared viscous liquid PDMS. After leaving the samples for $24 \mathrm{hrs}$, the PDMS polymers that held the negative replica of the original 
patterns were peeled off the Ti6Al4V sheets. Fig. 1 shows the schematic diagram of surface preparation.

\section{Table 1}

Laser scanning parameters for inducing two different surface textures on Ti-alloy substrate. Ti1 and Ti2 are two surface topographies generated using two different laser processing parameters.

\begin{tabular}{|c|c|c|c|}
\hline Surface & $\begin{array}{c}\text { Fluence } \\
{\left[\mathbf{J} / \mathbf{c m}^{2}\right]}\end{array}$ & $\begin{array}{c}\text { Scanning speed } \\
{[\mathbf{m m} / \mathbf{s}]}\end{array}$ & $\begin{array}{c}\text { Hatch distance } \\
{[\boldsymbol{\mu m}]}\end{array}$ \\
\hline Control & None & None & None \\
\hline Ti1 & 0.178 & 10 & 10 \\
\hline T2 & 0.138 & 1 & 10 \\
\hline
\end{tabular}

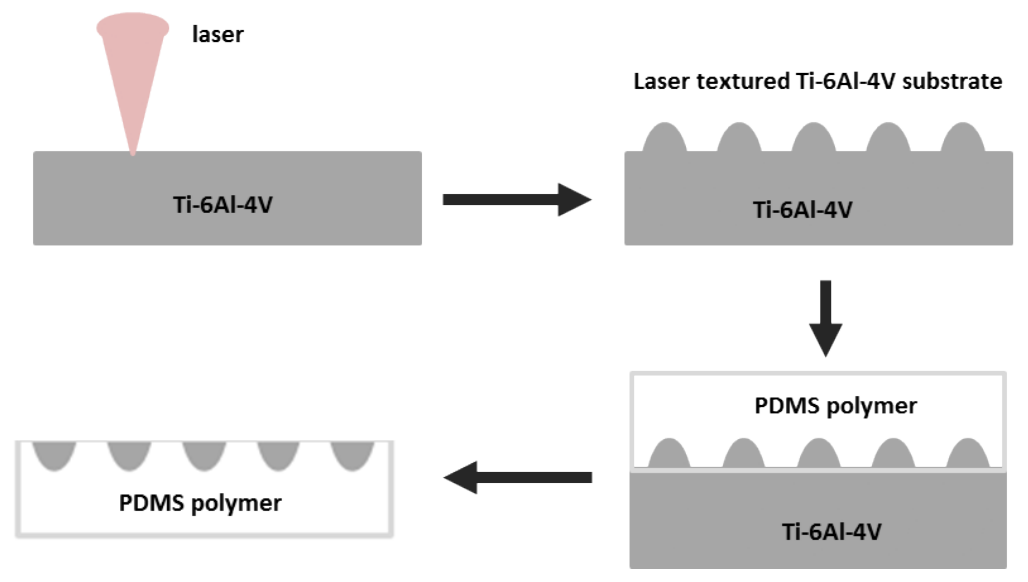

Fig. 1. Schematic diagram of surface preparation. Ps laser textured the Ti-alloy surface for generating micro/nano-textures (Ti1 \& Ti2). Then using soft replication method, the negative replica of Ti structures were produced on PDMS polymer substrate.

\subsection{Surface characterisation}

Following the replication of the Ti surface on the PDMS polymer sheet, the nanostructured surfaces were morphologically characterised using Philips XL30 FEG-SEM (SEM). The surfaces were examined using Keyence X200K, a 3D confocal laser microscope (CLM) (KEYENCE, USA) fitted with a $150 \mathrm{X}$ objective lens to determine the substratum macro- and micro-topographies. The instrument control and data analysis were performed using VK analyser software (KEYENCE, USA). Values of $R_{a}$ (average surface roughness), $R_{q}$ (root mean square roughness) and $R_{p v}$ (peak to valley roughness) were recorded for each tested surface. Also, selected line scans were used to determine the surface nanostructure height, depth and width of the peaks and valleys. 


\subsection{Wettability measurements}

Static contact angle (CA) measurements were performed via a drop sessile method using a contact angle analyser FTA 188. Briefly; $6 \mu 1$ droplets of DIW were allowed to contact the prepared Ti and PDMS surfaces. The average contact angles were recorded. All measurements were performed in triplicate.

\subsection{Bacterial retention examination}

A single colony of $S$. aureus (ATCC, 43,300 methicillin-resistant strains) was inoculated in one hundred millilitres of lysogeny broth (LB) (Sigma-Aldrich, Dorset, UK) and incubated with shaking overnight for $24 \mathrm{hrs}$ at $37^{\circ} \mathrm{C}$. Following the incubation, cells were harvested at 3500 rpm for 10 minutes. Subsequently, the harvested cells were washed three times and resuspended up to an optical density $(\mathrm{OD})=1.0 \pm 0.1$ at $540 \mathrm{~nm}$ in lysogeny broth (LB). A serial dilution was used to count the average colony forming units per millilitre (CFU/ml). Then, $10^{6}$ dilutions were chosen. The prepared surfaces and the control (without texturing) were sterilised using ethanol then placed into sterile petri dishes. An amount of $25 \mathrm{~mL}$ of cell suspension at $\mathrm{OD}=1.0$ was added, and the surfaces were incubated for $24 \mathrm{hrs}$ at $37^{\circ} \mathrm{C}$ without agitation. The surfaces were washed gently with distilled water using a water bottle at a $45^{\circ}$ angle, with a 3 $\mathrm{mm}$ nozzle. The surfaces were then dried in a laminar flow hood for $1 \mathrm{hr}$, and then the samples were prepared for SEM examination. After drying the samples bearing cells, they were immersed in a $4 \%$ glutaraldehyde (Agar, UK) solution at $4{ }^{\circ} \mathrm{C}$ overnight. The samples were immersed sequentially in each of the following ethanol (Sigma-Aldrich, UK)/water mixtures (30\%, $50 \%, 70 \%, 90 \%$ and $100 \% \mathrm{v} / \mathrm{v}$ ethanol) for 10 minutes and then dried for $1 \mathrm{hr}$. Imaging was performed using a Philips XL30 FEG-SEM and 10,000X magnification. Three replicate substrates were tested. Five different areas were imaged using the SEM for each coupon totalling final number cell counts $(n=15)$ for each tested surface.

\section{Results}

Picosecond laser ablation was used to fabricate periodic 3D nanostructures on titanium. SEM images and confocal laser microscope images of the surfaces demonstrated that the Ti6A14V surface had been altered, through melting, vaporisation and solidification to produce a range of different regular surface features at the macro/microscale. Fig. 2a-c present respective SEM micrographs of the Ti6A14V surfaces after laser texturing. It is clear that the control surface had a shot-finished irregular structure with convex pits (Fig. 2a, a1 and a2). The Til surface demonstrated surface features that were long and oval in length with striations in between the 
surface features (ripples or laser-induced periodic surface structures, LIPSS), (Fig. 2b, b1 and b2). The Ti2 surface revealed the largest overall surface features that were generally rounded with non-uniform circumferences (Fig. 2c, c1 and c2). These properties were subsequently negatively transferred to PDMS-replicated surface as presented in Fig. 2d-f. It is clear that the control surface was more of a flat-finished one with some irregular peaks (Fig. 2d, d1 and d2). S1 was the polymer replica of Ti1 and S2 was the polymer replica of Ti2. The S1 surface (Fig. 2e, e1 and e2) showed surface features with periodic structures and sharp irregular peaks intervening between them. The S2 surface (Fig. 2f, f1 and f2) revealed surface features that appeared as rounded non-uniform holes covered with submicron holes. 

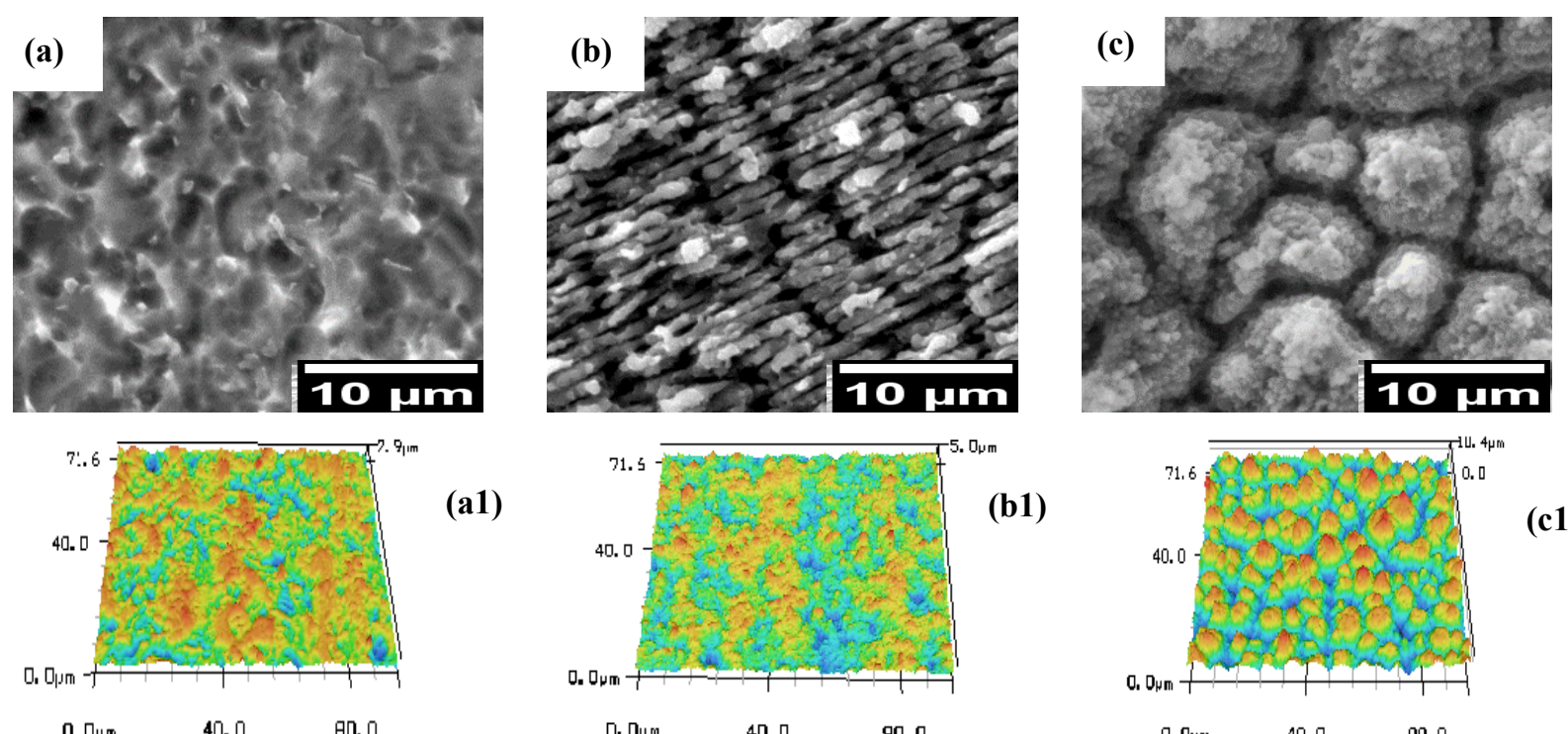

(a1)
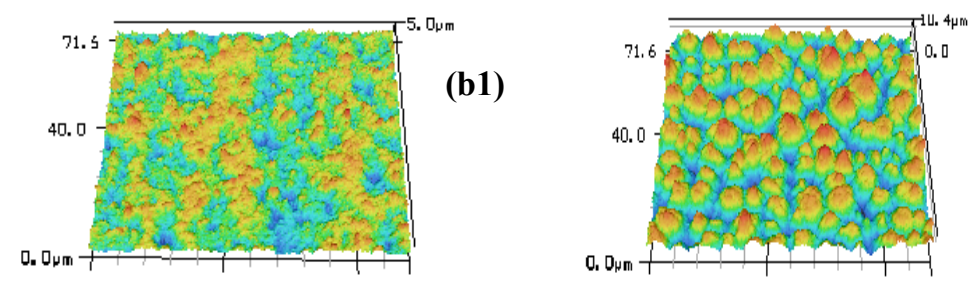

(c1)
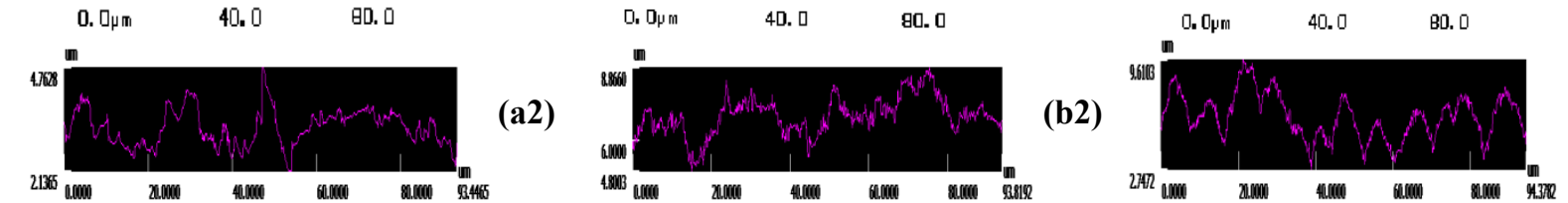

(d)
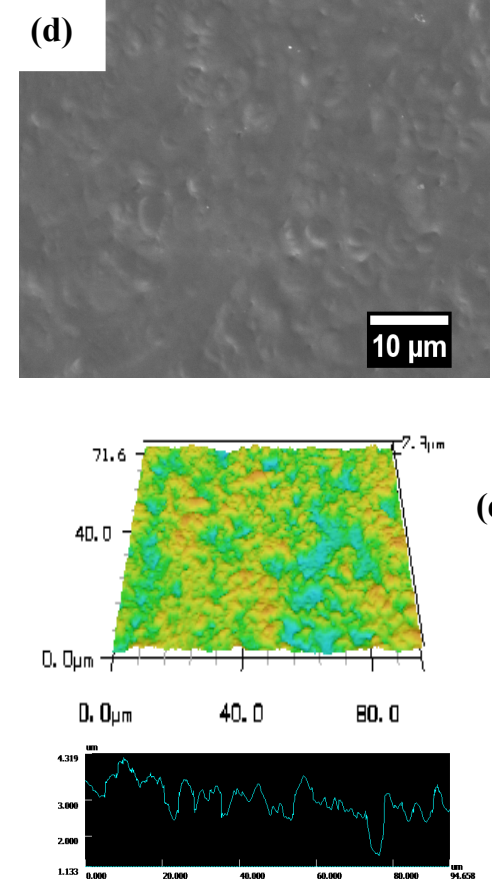

(d1)
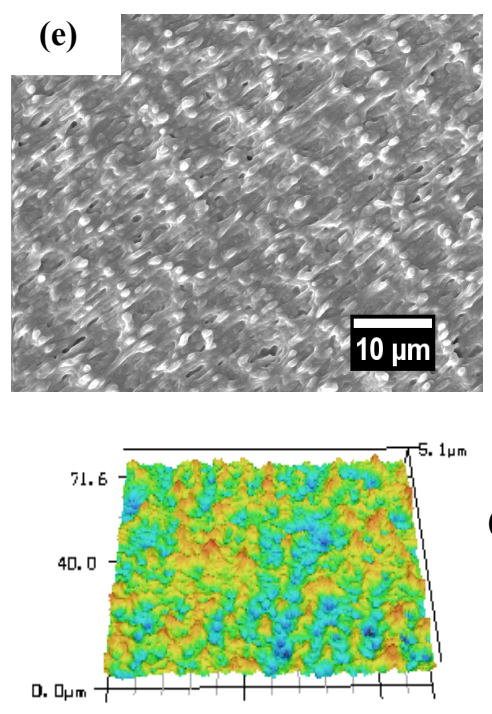

0. $\square \mu \mathrm{m}$

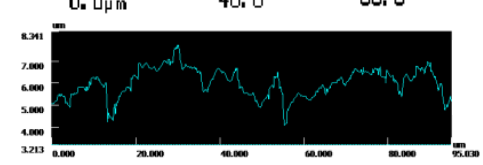

(e1)
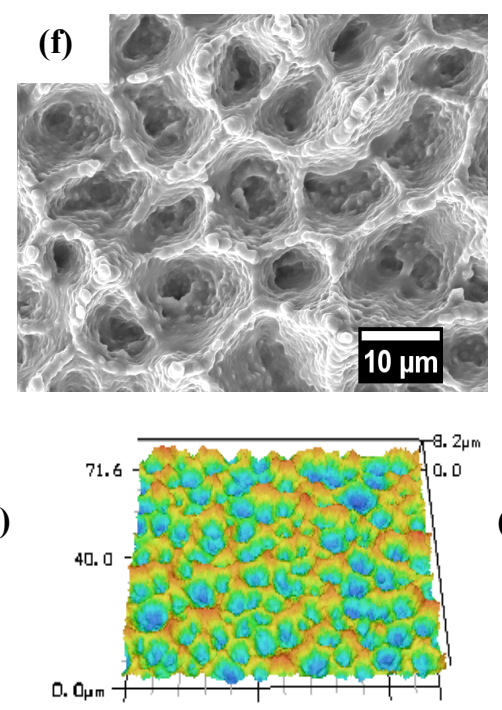

(f1)

(e2)

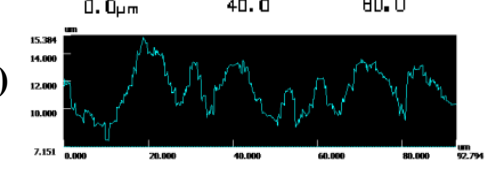

Fig. 2. SEM images and surface topography of (a) as received control Ti-alloy surface, (b) laser-textured Tialloy surfaces (Ti1), (c) laser-textured Ti-alloy surface (Ti2), (a1) 3D CLM image of Ti control, (b1) 3D CLM image of Ti1, (c1) 3D CLM image of Ti2, (a2) line profile of Ti control, (b2) line profile of Ti1, (c2) line profile of Ti2, (d) replicated untreated Ti control on PDMS surface, (e) replicated Ti1 on PDMS surface (S1), (f) replicated Ti2 on PDMS surface (S2), (d1) 3D CLM image of PDMS control, (e1) 3D CLM image of S1, (f1) 3d CLM image of S2, (d2) line profile of PDMS control, (e2) line profile of S1 and (f2) line profile of S2. 
On the one hand, the line profile of laser-textured Ti surfaces (Fig. 2a2-c2) showed that the maximum (peaks width / height, valleys width / height) of the control, Ti1 and Ti2 were (1.7 / $0.4,3.0 / 0.3),(1.4 / 0.8,1.1 / 0.3)$ and $(2.5 / 0.9,3.3 / 0.8)$, respectively. The line profile of the PDMS-replicated surfaces (Fig. 2d2-f2), on the other hand, demonstrated that the maximum (peaks width / height, valleys width / height) of the control, S1 and S2 were $(3.2$ / 0.4, 1.66 / $0.36),(1.11 / 0.3,1.34 / 0.7)$ and $(3.1 / 0.68,2.1 / 0.74)$, respectively. Once again the surface features of the Ti2 surface and its replication (S2), in terms of the peak (width and height) and the valley (width and depth), were the largest in size. The roughness values for the surfaces demonstrated that the control Ti surface had the lowest $R_{a}$ value $(0.29 \mu \mathrm{m})$ of the laser-treated Ti samples. There was a significant difference in surface roughness between the control surface and Ti1 $(0.52 \mu \mathrm{m})$ and Ti2 $(1.38 \mu \mathrm{m})$. The control PDMS surface also presented the lowest $R_{a}$ $(0.33 \mu \mathrm{m})$, compared with the PDMS-replicated surfaces, and there was a significant difference between the $R_{a}$ values for the S1 $(0.495 \mu \mathrm{m})$ and S2 $(1.032 \mu \mathrm{m})$ surfaces (Fig. 3). The $R_{q}$ values for the laser-texture surfaces, Ti1 $(0.68 \mu \mathrm{m}), \mathrm{Ti} 2(1.41 \mu \mathrm{m}), \mathrm{S} 1(0.634 \mu \mathrm{m})$ and $\mathrm{S} 2(1.265 \mu \mathrm{m})$, were also significantly greater than the control Ti $(0.374 \mu \mathrm{m})$ and the control PDMS $(0.414$ $\mu \mathrm{m})$. The $R_{p v}$ (peak to valley roughness) values obtained for Ti2 $(9.37 \mu \mathrm{m})$ and $\mathrm{S} 2(8.7 \mu \mathrm{m})$ were significantly higher than the one obtained for Ti-alloy control $(3.28 \mu \mathrm{m})$ and the PDMS control $(3.642 \mu \mathrm{m})$. The replicated control PDMS surface presented a slightly higher $R_{a}, R_{q}$ and $R_{p v}$ values, comparative to control $\mathrm{Ti}$, while $\mathrm{S} 1$ and $\mathrm{S} 2$ presented smaller values compared to Ti1 and Ti2. 


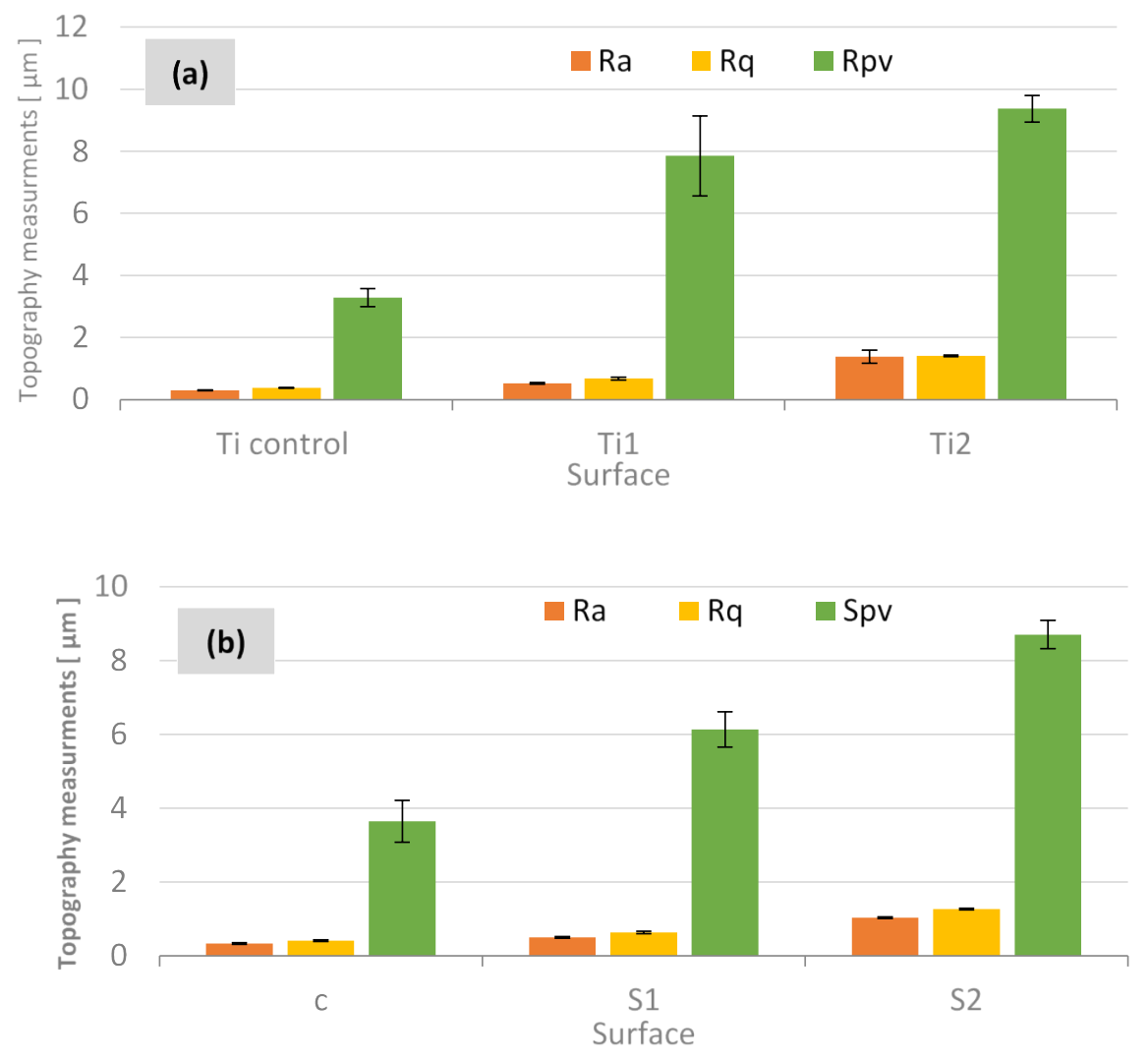

Fig. 3. Surface roughness values using confocal laser microscopy for (a) the laser-textured Ti surfaces compared to unmodified substrate and (b) PDMS-replicated surfaces compared to control PDMS.

Fig. 4 presents the water contact angles of laser-textured surfaces (Fig. 4a) after one month of laser processing and replicated PDMS surface (Fig. 4b). It is clear that the laser-modified surfaces (Ti1 and Ti2) and the PDMS replicated surfaces (S1 and S2) presented higher contact angles, when compared to unmodified Ti surface and its PDMS replication. Surface structuring increased the contact angle from $83.07^{\circ} \pm 2.7^{\circ}$ to $130.8^{\circ} \pm 3.5^{\circ}$ on $\mathrm{Ti}$, and from $102.42^{\circ} \pm 3.51^{\circ}$ to $148.33^{\circ} \pm 1^{\circ}$ on PDMS. After laser treatment, the Ti surfaces were initially superhydrophilic with $\mathrm{CA}=0^{\circ}$; they changed to be hydrophobic two months after the laser processing. Linking the wettability data with surface roughness date (Fig. 3), it is clear that structuring the surface increased the surface roughness and decreased the surface wettability. The wettability of the replicated PDMS surfaces presented a slightly higher CA than the CA of the laser-textured Ti surfaces. 

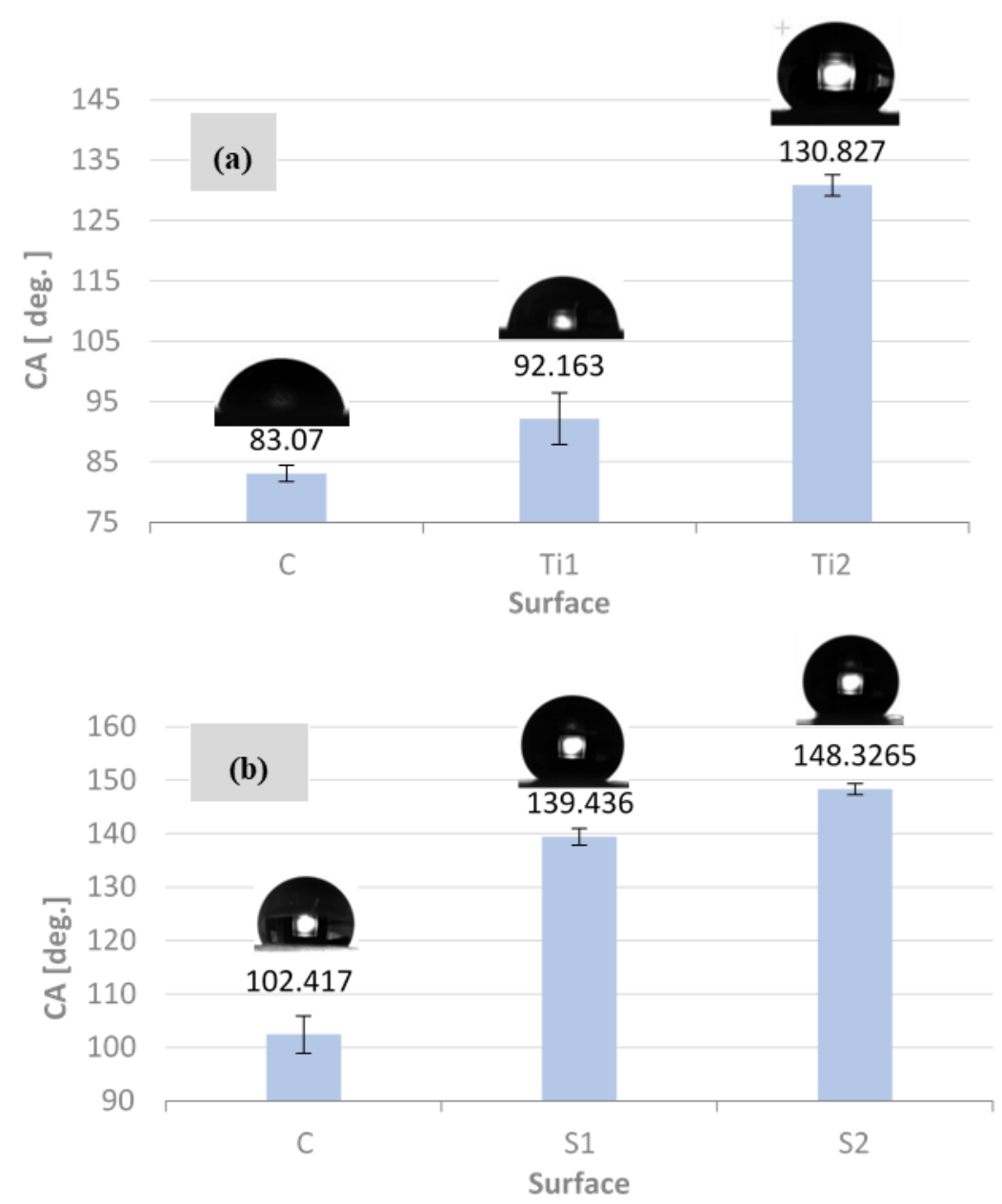

Fig. 4. Contact angle measurements of laser textured surface (a) and replicated PDMS surfaces (b). The contact angle of structured surfaces is higher than that unmodified surface. C for PDMS unstructured surface.

The test of bacterial attachment and retention was carried out for the replicated PDMS surfaces. Following the bacterial assay, it was found that there was a significant difference in the attachment of bacteria on the replicated PDMS surfaces (S1 and S2), when compared to the control PDMS surface without surface texture (Fig. 5). The bacteria attached to the control surfaces were arranged in clusters; whereas, they were spreaed over the S1 and S2 surfaces. Following the retention assays, the number of adhered cells, after incubation for $24 \mathrm{hrs,} \mathrm{was}$ significantly different on all the surfaces with the least number of cells ( 15 cells) being adhered to the S2 surface, followed by the S1 surface (51 cells). There were significantly more cells adhered to the control surface (82 cells) compared with S1 and S2 (Fig. 6). 


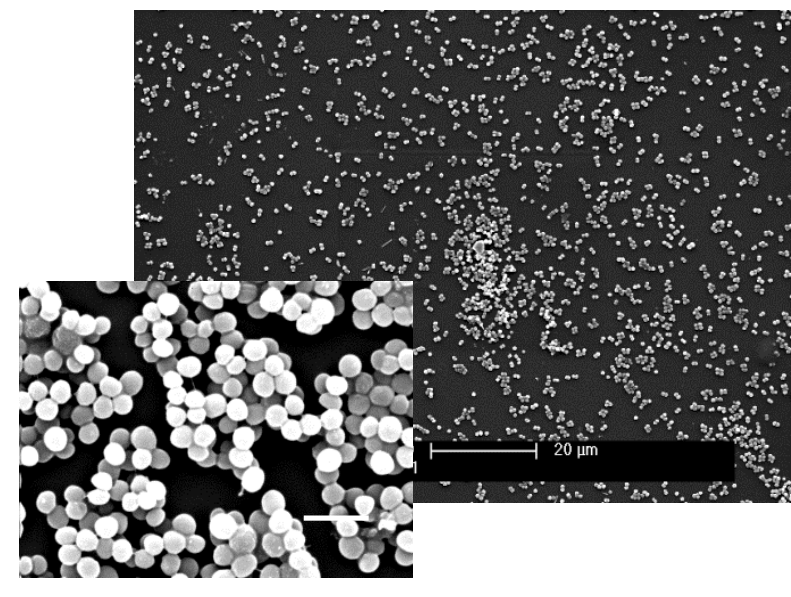

(a)

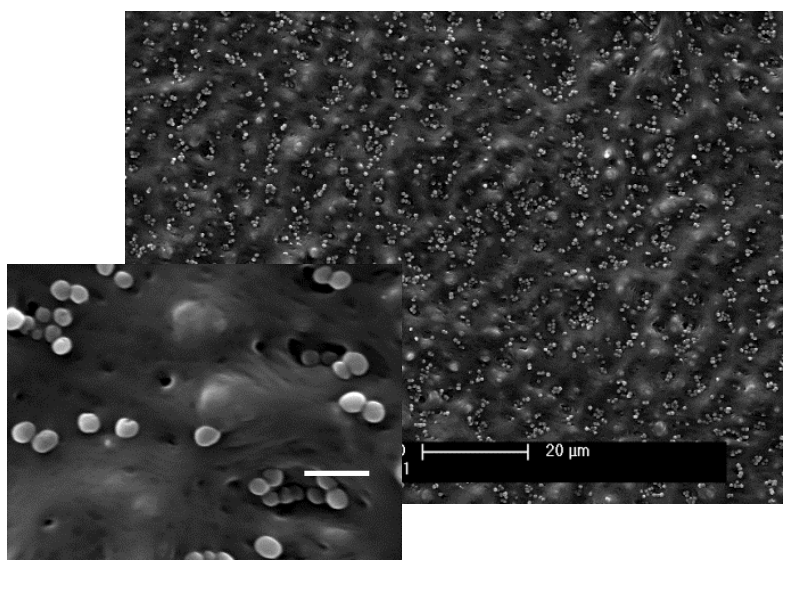

(b)

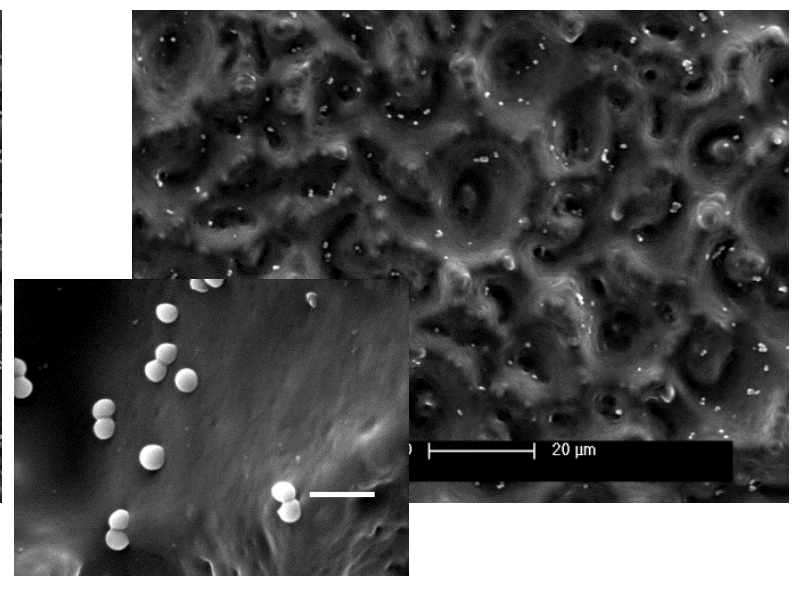

(c)

Fig. 5. SEM images of PDMS replicated surfaces following retention assay on (a) control unstructured PDMS surface, (b) S1 and (c) S2; white scale bar is $2 \mu \mathrm{m}$. 


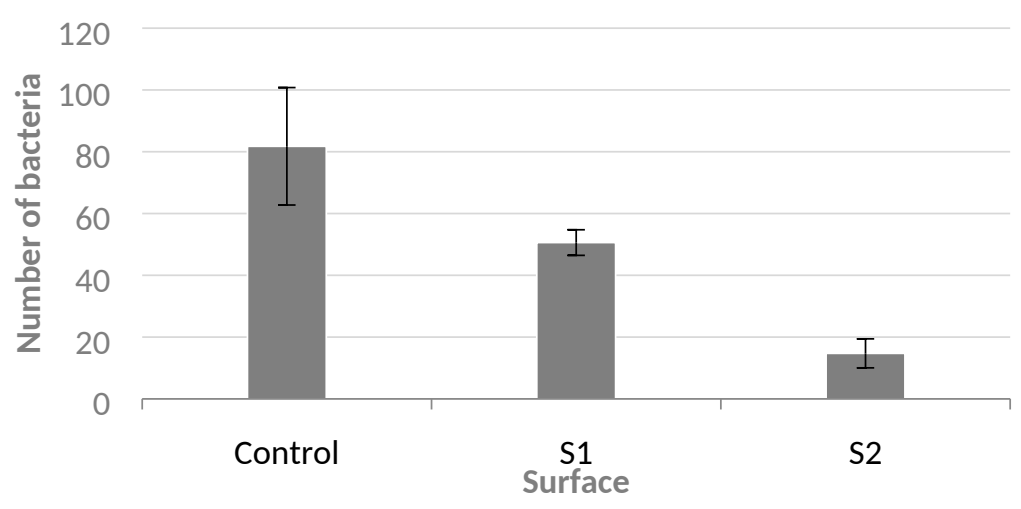

Fig. 6. The average number of bacteria retained on the surfaces following retention assays. S2 showed less number of attached bacteria comparing with S1 and unstructured PDMS surfaces.

\section{Discussion}

An understanding of how surface properties affect retention of bacteria helps in designing or modifying surfaces to discourage bacterial fouling. Modifying the metal surfaces and replicating the structure to a polymer material is an efficient way of minimising the manufacturing time and cost for producing surfaces for different industrial and medical applications. In this work, the laser-textured Ti-alloy structures were replicated on PDMS polymer using soft lithography.

Different surface structures were produced on the Ti6Al4V surface depending on the used laser treatment parameters. During the ultrashort laser exposure, a significant proportion of the laser energy was absorbed by the free electrons resulting from a thermalisation process [42]. At sufficient laser fluence, surface modification as a result of ablation, melting and solidification can take place. The change of surface morphology and roughness of the laser-textured samples is related to the change in laser scanning parameters including pulse energy, the extent of line overlapping, the number of pulses per spot, and the physiothermal properties of the substrate being treated. In the current study, pulse overlapping was estimated to be $99.92 \%$ and 99.99 $\%$ at scan speeds of $10 \mathrm{~mm} / \mathrm{s}$ (Ti1) and $1 \mathrm{~mm} / \mathrm{s}$ (Ti2), respectively. Line overlapping was estimated to be $92 \%$ at a respective hatch distance of $10 \mu \mathrm{m}$. Pulses per spot were estimated to be 1290 (Ti1) and 12900 (Ti2). As the overlapping and the number of pulses were high, the greater laser energy input produced a heat accumulation effect that resulted in the different observed structures. Using a higher scanning speed of $10 \mathrm{~mm} / \mathrm{s}$ to produce the Ti1 surface, the extent of pulse overlapping was lower than that estimated using $1 \mathrm{~mm} / \mathrm{s}$ and thus the thermal effect was relatively low, which resulted in the generation of structures with a lower surface roughness. This structure was characterised as a (LIPSS). The formation of the narrow peaks 
was due to rapid cooling of overheating liquid explosion, and re-solidification [43]. In the case of $\mathrm{Ti} 2$, the generated structure of the surface after the laser processing was characterised as conical. As this surface was prepared, using a $1 \mathrm{~mm} / \mathrm{s}$ scanning speed and $10 \mu \mathrm{m}$ hatch distance, the pulse overlapping of laser was high, resulting in higher amount of energy deposted over a small surface area which in turn may have resulted in enhancement of absorption of laser energy. Following the first pulse, re-solidified particles formed. The upcoming pulses hit the same area of the first pulse. Therefore, enhancement of energy absorption and local overheating occurred owing to a nearfield enhancement mechanism resulting in local heating of the material, melting and ablation forming these conical structures [44, 45]. The rounded conical structure was covered by sub-micron features which were formed as a result of sintering of particles of ablated substrates [46].

The replicated negative surfaces presented different structures which were the opposite of the laser-textured Ti surfaces. In the case of S1, the surface presented periodic structures with some peaks between them. These periodic structures were the replication of the LIPSS structure while the small peaks were the replication of sub-micron holes of Ti1. Regarding S2, the surface presented big craters with sub-micron holes covering the area of the big craters. The big crater structure represented the opposite of conical structure, and the small sub-micron holes were the replication of sub-micron features that covered the conical structure of Ti2. By comparing the negative replicas with original Ti surfaces (Fig. 3), it was clear that there was not high difference between the surfaces roughness values between original Ti surfaces and polymer replicas. The replicated control PDMS surface presented a slightly higher $R_{a}, R_{q}$ and $R_{p v}$ values, comparative to control $\mathrm{Ti}$, while $\mathrm{S} 1$ and $\mathrm{S} 2$ presented slightly smaller values compared to Ti1 and Ti2. Indeed, this reflects the accuracy of using this method in replication process. The accuracy of replication method might be related to the wettability of Ti surfaces and the used polymer since the surfaces after laser treatment were superhydrophilic, the polymer was easily penetrated in the features resulting in good accuracy of replication.

It was noticed that for all produced surfaces (laser-textured Ti surfaces and replicated PDMS surfaces) with the roughness inceased, the wettability decreased as a result of increasing the air trapped between features of the surface. Surfaces of higher roughness (for samples prepared using Ti2 and its PDMS replicated surface) were of lower wettability. This behaviour can be explained by the Cassie state because such surfaces have a large roughness consisting of nanostructures combined with sub-micron and nanostructures. A layer of air was trapped between features preventing wetting of the surfaces. These findings was in line with the 
findings by Cheng et al (2013) [47] who showed that an increase the roguhness also increased the air trapping which in turn affected the CA. It was also noticed that with decreasing the surface roughness (by increasing the speed to $10 \mathrm{~mm} / \mathrm{s}$ ), the contact angle (CA) was slightly decreased. The CA of PDMS replicated surfaces showed a slightly higher CA than those of the laser-textured surfaces. This might be related to the low surface tension of polymer in comparison with metals [48].

In this work, it was observed that the number of adhered bacteria to the surface was low on the replicated patterned polymer, compartive to the control. Replicated textured polymer reduced the bacterial adhesion by $38 \%$ (S1) to $82 \%$ (S2) compared with the unpattered PDMS surface (control). Bacterial adhesion and fouling on surfaces with various topographies have been extensively studied before. However, there has been no general consensus concerning the effect of surface topography on bacterial retention. This may be owing to the range of examined topographies (nano, micro and macro) and other associated changes to the surface properties. It has been reported that the retention of microorganism might increase with increasing surface roughness due to larger surface areas [49]. With increasing surface roughness of the correct size scale, the contact area between the surface of the microorganism and the substrate increases, which may enhance the attachment of bacteria [50]. Conversely, other studies concluded that there might be no correlation between surface roughness and bacterial retention $[5,51]$. The results of the current work show that bacterial retention was lower for the replicated surfaces with textures for the largest surface features and roughness. As such, the reduction of bacterial surface adhesion could be attributed to other reasons.

All the surfaces were hydrophobic, and the hydrophobicity was higher for the replicated surfaces with the texturing $\left(\mathrm{S} 1=139^{\circ}, \mathrm{S} 2=148^{\circ}\right)$ compared with unpattern polymer (control $=102^{\circ}$ ). By comparing the wettability test with bacteria adhesion test, it can be noticed that the bacterial adhesion decreased with increasing surface hydrophobicity and the highest surface hydrophobicity was associated with the lowest bacteria adhesion on the replicate patterned PDMS surfaces. The results of this work are in line with several reported investigations in which it has been reported that the surface of higher hydrophobicity are more able to resist the bacterial cells compared with hydrophilic and moderate hydrophobic surfaces [52]. The results also was in harmony with Dou et al (2015) [53], Lu et al (2016) [9] and Friedlander et al (2013) [54] works in which the authors reported that that surfaces hydrophobicity play an important role in reducing the bacterial attachment. In this work, it was noticed that, after laser treatment, the roughness of the surface promoted the Cassie state of the patterned surfaces by maintaining 
of entrapped air between roughening features. This entrapped air layer may play an important role in suppressing bacterial adhesion to surfaces by reducing the contact area at the interface of the surface features and bacteria and hence leading to a decreasing adhesion force. Thus, for the replicated textured polymer surfaces (S1 and S2), as the surface roughness increased, air trapped between features was increased resulting in increasing the contact angle to more than $130^{\circ}$, and prevention of complete wetting through the surface which are possible reasons behind the reduction of the contact area between bacteria with the surface leading to less bacterial adhesion. Findings of this work was in line with Vasudevan et al (2014) [12] findings who reported that maintaining rough surface with Cassie state might hinder the bacterial attachment on polymer surfaces.

Multiple aspects of surface properties affect the adhesion of bacteria to surfaces. In this work, it has been concluded that surface wettabillity played important factors affecting bacterial adhesion. A small-scale roughness on a hydrophobic surface can hinder the contact of bacteria with the surface by the entrapping air between features of the surface, and a washing such surfaces might allow an easy removal of adhered bacteria. The results of this study might provide guidance for the future development of antibacterial materials

\section{Conclusions}

In this study, ultrashort picosecond laser micro-/nano-fabrication was used to form micro/nanostructures on a metallic mould surface and transferred to plastic by soft replication. The findings of this work showed that the laser-irradiated Ti-alloy formed hydrophobic surfaces with contact angles of approximately $130^{\circ}$. The replication on plastic showed that soft replications can accurately replicate patterns from the metallic master to the plastic replica. The functionality of PDMS-negative mold CA was also close to a superhydrophobic reading at around $149^{\circ}$. The surface hydrophobicity resulted in a superior antiadhesive PDMS surface and bacterial retention was much reduced. This approach of laser surface structuring and soft replication presented in this work provides a highly efficient, low-cost, and highly reproducible strategy for the development of hydrophobic and antiadhesive surfaces on polymeric materials by replication from metallic moulds or stamps.

\section{Acknowledgements}

The authors acknowledge Iraqi Ministry of Higher Education and Scientific Research (MOHESR) for the financial support of Fatema Rajab's $\mathrm{PhD}$ research. 


\section{Refrences}

[1] K.A. Whitehead, J. Verran, The effect of surface topography on the retention of microorganisms, Food and Bioproducts Processing 84(4) (2006) 253-259.

[2] M.S. Chae, H. Schraft, L.T. Hansen, R. Mackereth, Effects of physicochemical surface characteristics of Listeria monocytogenes strains on attachment to glass, Food microbiology 23(3) (2006) 250-259.

[3] P. Chavant, B. Martinie, T. Meylheuc, M.-N. Bellon-Fontaine, M. Hebraud, Listeria monocytogenes LO28: surface physicochemical properties and ability to form biofilms at different temperatures and growth phases, Applied and environmental microbiology 68(2) (2002) 728-737.

[4] H.D. Mortensen, K. Gori, L. Jespersen, N. Arneborg, Debaryomyces hansenii strains with different cell sizes and surface physicochemical properties adhere differently to a solid agarose surface, FEMS microbiology letters 249(1) (2005) 165-170.

[5] F.H. Rajab, C.M. Liauw, P.S. Benson, L. Li, K.A. Whitehead, Production of hybrid macro/micro/nano surface structures on Ti6Al4V surfaces by picosecond laser surface texturing and their antifouling characteristics, Colloids and Surfaces B: Biointerfaces 160 (2017) 688-696.

[6] F.H. Rajab, C.M. Liauw, P.S. Benson, L. Li, K.A. Whitehead, Picosecond laser treatment production of hierarchical structured stainless steel to reduce bacterial fouling, Food and Bioproducts Processing 109 (2018) 29-40.

[7] F. Rajab, P. Benson, L. Li, K. Whitehead, Picosecond Laser Surface Micro/Nano Texturing of Stainless Steel as a Method to Reduce the Adhesion of Bacteria, Proceedings of LPM2017-the 18th International Symposium on Laser Precision Microfabrication, 2017.

[8] L.-C. Xu, C.A. Siedlecki, Submicron-textured biomaterial surface reduces staphylococcal bacterial adhesion and biofilm formation, Acta biomaterialia 8(1) (2012) 72-81.

[9] N. Lu, W. Zhang, Y. Weng, X. Chen, Y. Cheng, P. Zhou, Fabrication of PDMS surfaces with micro patterns and the effect of pattern sizes on bacteria adhesion, Food control 68 (2016) 344-351.

[10] L.-C. Xu, Y. Wo, M.E. Meyerhoff, C.A. Siedlecki, Inhibition of bacterial adhesion and biofilm formation by dual functional textured and nitric oxide releasing surfaces, Acta biomaterialia 51 (2017) 53-65.

[11] M. Fernández, M. Casabona, V. Anupama, B. Krishnakumar, G. Curutchet, D. Bernik, PDMS-based porous particles as support beds for cell immobilization: bacterial biofilm formation as a function of porosity and polymer composition, Colloids and Surfaces B: Biointerfaces 81(1) (2010) 289-296.

[12] R. Vasudevan, A.J. Kennedy, M. Merritt, F.H. Crocker, R.H. Baney, Microscale patterned surfaces reduce bacterial fouling-microscopic and theoretical analysis, Colloids and Surfaces B: Biointerfaces 117 (2014) 225-232.

[13] E. Fadeeva, V.K. Truong, M. Stiesch, B.N. Chichkov, R.J. Crawford, J. Wang, E.P. Ivanova, Bacterial retention on superhydrophobic titanium surfaces fabricated by femtosecond laser ablation, Langmuir 27(6) (2011) 3012-3019.

[14] M. Kargar, J. Wang, A.S. Nain, B. Behkam, Controlling bacterial adhesion to surfaces using topographical cues: a study of the interaction of Pseudomonas aeruginosa with nanofiber-textured surfaces, Soft Matter 8(40) (2012) 10254-10259. 
[15] M. Kargar, Y.-R. Chang, H. Khalili Hoseinabad, A. Pruden, W.A. Ducker, Colloidal Crystals Delay Formation of Early Stage Bacterial Biofilms, ACS Biomaterials Science \& Engineering 2(6) (2016) 1039-1048.

[16] S.M. Kelleher, O. Habimana, J. Lawler, B. O’reilly, S. Daniels, E. Casey, A. Cowley, Cicada wing surface topography: an investigation into the bactericidal properties of nanostructural features, ACS applied materials \& interfaces 8(24) (2015) 14966-14974.

[17] K. Manabe, S. Nishizawa, S. Shiratori, Porous surface structure fabricated by breath figures that suppresses Pseudomonas aeruginosa biofilm formation, ACS applied materials \& interfaces 5(22) (2013) 11900-11905.

[18] E. Preedy, S. Perni, D. Nipiĉ, K. Bohinc, P. Prokopovich, Surface roughness mediated adhesion forces between borosilicate glass and gram-positive bacteria, Langmuir 30(31) (2014) 9466-9476.

[19] D. Perera-Costa, J.M. Bruque, M.L. González-Martín, A.C. Gómez-García, V. VadilloRodríguez, Studying the influence of surface topography on bacterial adhesion using spatially organized microtopographic surface patterns, Langmuir 30(16) (2014) 4633-4641.

[20] M. Abrigo, P. Kingshott, S.L. McArthur, Electrospun polystyrene fiber diameter influencing bacterial attachment, proliferation, and growth, ACS applied materials \& interfaces 7(14) (2015) 7644-7652.

[21] K.A. Whitehead, J. Colligon, J. Verran, The production of surfaces of defined topography and chemistry for microbial retention studies, using ion beam sputtering technology, International biodeterioration \& biodegradation 54(2) (2004) 143-151.

[22] K.A. Whitehead, J. Colligon, J. Verran, Retention of microbial cells in substratum surface features of micrometer and sub-micrometer dimensions, Colloids and Surfaces B: Biointerfaces 41(2) (2005) 129-138.

[23] A.Y. Vorobyev, C. Guo, Direct femtosecond laser surface nano/microstructuring and its applications, Laser \& Photonics Reviews 7(3) (2013) 385-407.

[24] S. Schlie, E. Fadeeva, J. Koch, A. Ngezahayo, B.N. Chichkov, Femtosecond laser fabricated spike structures for selective control of cellular behavior, Journal of biomaterials applications 25(3) (2010) 217-233.

[25] M. Kreisler, W. Kohnen, C. Marinello, H. Götz, H. Duschner, B. Jansen, B. D'Hoedt, Bactericidal effect of the Er: YAG laser on dental implant surfaces: an in vitro study, Journal of periodontology 73(11) (2002) 1292-1298.

[26] C. De Giorgi, V. Furlan, A.G. Demir, E. Tallarita, G. Candiani, B. Previtali, Laser micropolishing of AISI 304 stainless steel surfaces for cleanability and bacteria removal capability, Applied Surface Science 406 (2017) 199-211.

[27] J. Gold, B. Nilsson, B. Kasemo, Microfabricated metal and oxide fibers for biological applications, Journal of Vacuum Science \& Technology A 13(5) (1995) 2638-2643.

[28] A. Gaggl, G. Schultes, W. Müller, H. Kärcher, Scanning electron microscopical analysis of laser-treated titanium implant surfaces - a comparative study, Biomaterials 21(10) (2000) 1067-1073.

[29] G. Pető, A. Karacs, Z. Pászti, L. Guczi, T. Divinyi, A. Joób, Surface treatment of screw shaped titanium dental implants by high intensity laser pulses, Applied Surface Science 186(1) (2002) 7-13. 
[30] C. Herrmann, S. Thiede, Process chain simulation to foster energy efficiency in manufacturing, CIRP Journal of Manufacturing Science and Technology 1(4) (2009) 221229.

[31] M. Weck, T. Pfeifer, C. Brecher, R. Schmitt, D. Dörner, M. Winterschladen, Approach to a Machine-Integrated Measurement and Simulation Tool for the Manufacturing of ultra precise Surfaces, Annals of the WGP 12(1) (2005) 133-136.

[32] J. Bekesi, J. Kaakkunen, W. Michaeli, F. Klaiber, M. Schoengart, J. Ihlemann, P. Simon, Fast fabrication of super-hydrophobic surfaces on polypropylene by replication of short-pulse laser structured molds, Applied Physics A 99(4) (2010) 691-695.

[33] P. Wu, C. Cheng, C. Chang, T. Wu, J. Wang, Fabrication of large-area hydrophobic surfaces with femtosecond-laser-structured molds, Journal of Micromechanics and Microengineering 21(11) (2011) 115032.

[34] T. Jiang, J. Koch, C. Unger, E. Fadeeva, A. Koroleva, Q. Zhao, B.N. Chichkov, Ultrashort picosecond laser processing of micro-molds for fabricating plastic parts with superhydrophobic surfaces, Applied Physics A 108(4) (2012) 863-869.

[35] J. Noh, J.-H. Lee, S. Na, H. Lim, D.-H. Jung, Fabrication of hierarchically micro-and nano-structured mold surfaces using laser ablation for mass production of superhydrophobic surfaces, Japanese Journal of Applied Physics 49(10R) (2010) 106502.

[36] G. Davaasuren, C.-V. Ngo, H.-S. Oh, D.-M. Chun, Geometric study of transparent superhydrophobic surfaces of molded and grid patterned polydimethylsiloxane (PDMS), Applied Surface Science 314 (2014) 530-536.

[37] G. Römer, A. Huis, J. Meijer, M. Groenendijk, On the formation of laser induced selforganizing nanostructures, CIRP annals 58(1) (2009) 201-204.

[38] S. Sarbada, Y.C. Shin, Superhydrophobic contoured surfaces created on metal and polymer using a femtosecond laser, Applied Surface Science 405 (2017) 465-475.

[39] D.-M. Chun, G. Davaasuren, C.-V. Ngo, C.-S. Kim, G.-Y. Lee, S.-H. Ahn, Fabrication of transparent superhydrophobic surface on thermoplastic polymer using laser beam machining and compression molding for mass production, CIRP Annals-Manufacturing Technology 63(1) (2014) 525-528.

[40] D. Gong, J. Long, D. Jiang, P. Fan, H. Zhang, L. Li, M. Zhong, Robust and stable transparent superhydrophobic polydimethylsiloxane films by duplicating via a femtosecond laser-ablated template, ACS applied materials \& interfaces 8(27) (2016) 17511-17518.

[41] S. Perni, P. Prokopovich, Micropatterning with conical features can control bacterial adhesion on silicone, Soft Matter 9(6) (2013) 1844-1851.

[42] A. Ben-Yakar, A. Harkin, J. Ashmore, R.L. Byer, H.A. Stone, Thermal and fluid processes of a thin melt zone during femtosecond laser ablation of glass: the formation of rims by single laser pulses, Journal of Physics D: Applied Physics 40(5) (2007) 1447.

[43] B. Liu, W. Wang, G. Jiang, X. Mei, K. Wang, J. Wang, Formation of porous structure with subspot size under the irradiation of picosecond laser pulses, Journal of Nanomaterials 2013 (2013) 11.

[44] L. Li, W. Guo, Z. Wang, Z. Liu, D. Whitehead, B. Luk'yanchuk, Large-area laser nanotexturing with user-defined patterns, Journal of Micromechanics and Microengineering 19(5) (2009) 054002. 
[45] J. Schille, R. Ebert, U. Loeschner, P. Regenfuss, T. Suess, H. Exner, Micro structuring with highly repetitive ultra short laser pulses, Proc. 9th Int'1 Symp. Laser Prec.

Microfab.(LMP2008), 2008, pp. 08-57.

[46] Y. Li, Z. Cui, W. Wang, C. Lin, H.-L. Tsai, Formation of linked nanostructure-textured mound-shaped microstructures on stainless steel surface via femtosecond laser ablation, Applied Surface Science 324 (2015) 775-783.

[47] Z. Cheng, M. Du, H. Lai, N. Zhang, K. Sun, From petal effect to lotus effect: a facile solution immersion process for the fabrication of super-hydrophobic surfaces with controlled adhesion, Nanoscale 5(7) (2013) 2776-2783.

[48] J. Yong, F. Chen, Q. Yang, X. Hou, Femtosecond laser controlled wettability of solid surfaces, Soft Matter 11(46) (2015) 8897-8906.

[49] J. Holah, R. Thorpe, Cleanability in relation to bacterial retention on unused and abraded domestic sink materials, Journal of Applied Bacteriology 69(4) (1990) 599-608.

[50] D. Timperley, R. Thorpe, J. Holah, Implications of engineering design in food industry hygiene, Biofilms - Science and Technology, Springer1992, pp. 379-393.

[51] S. Flint, N. Hartley, A modified selective medium for the detection of Pseudomonas species that cause spoilage of milk and dairy products, International Dairy Journal 6(2) (1996) 223-230.

[52] Y. Yuan, M.P. Hays, P.R. Hardwidge, J. Kim, Surface characteristics influencing bacterial adhesion to polymeric substrates, RSC Advances 7(23) (2017) 14254-14261.

[53] X.-Q. Dou, D. Zhang, C. Feng, L. Jiang, Bioinspired hierarchical surface structures with tunable wettability for regulating bacteria adhesion, ACS nano 9(11) (2015) 10664-10672.

[54] R.S. Friedlander, H. Vlamakis, P. Kim, M. Khan, R. Kolter, J. Aizenberg, Bacterial flagella explore microscale hummocks and hollows to increase adhesion, Proceedings of the National Academy of Sciences 110(14) (2013) 5624-5629. 